\title{
Privileges of Pharmacist in Saudi Arabia: Clinical and Administrative Activities
}

Faisal Al-Otaibi, Ph. D, Assistant Professor, College of Pharmacy, Pharmacy Patrice Department, Shaqra University, Saudi Arabia. Mohamed Soliman Imam, Ph. D, Assistant Professor, Dean, College of Pharmacy, Shaqra University, Saudi Arabia.

Randa Mansour Abdel-Sattar Ahmed, Ph.D, Biomedical Science Department, College of Pharmacy, Shaqra University, Saudi Arabia.

Amsha Alotaibi, Pharm D, Clinical Pharmacist, College of Pharmacy, Pharmacy Patrice Department, Shaqra University, Riyadh, Saudi Arabia.

Asma Alotaibi, Pharm D, Clinical Pharmacist College of Pharmacy, Pharmacy Practice Department, Shaqra University, Saudi Arabia. Amal Alotaibi, Pharm D, Clinical Pharmacist, College of Pharmacy, Shaqra University, Saudi Arabia.

Wesam Alsuwaid, Pharm D, Clinical Pharmacist, College of Pharmacy, Pharmacy Practice Department, Shaqra University, Saudi Arabia. Yousef Ahmed Alomi*, iD BSc. Pharm, MSc. Clin Pharm, BCPS, BCNSP, DiBA, CDE, Critical Care Clinical Pharmacists, TPN Clinical Pharmacist, Freelancer Business Planner, Content Editor and Data Analyst, P.O.BOX 100, Riyadh, Saudi Arabia.

\section{Correspondence:}

Dr. Yousef Ahmed Alomi, BSc. Pharm, MSC. Clin Pharm, BCPS, BCNSP, DiBA, CDE Critical Care Clinical Pharmacists, TPN Clinical Pharmacist, Freelancer Business Planner, Content Editor and Data Analyst, P.O.BOX 100,

Riyadh 11392, Riyadh, Saudi Arabia.

Phone no: +966504417712

E-mail: yalomi@gmail.com

Received: 18-06-2019;

Accepted: 25-09-2019.

Copyright: (c) the author(s),publisher and licensee Pharmacology, Toxicology and Biomedical Reports. This is an open-access article distributed under the terms of the Creative Commons Attribution NonCommercial License, which permits unrestricted non-commercial use, distribution, and reproduction in any medium, provided the original work is properly cited.

This is an open access article distributed under the terms of the Creative Commons Attribution-NonCommercial-ShareAlike 4.0 License

Access this article online

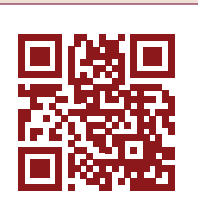

www.ptbreports.org

DOI:

10.5530/PTB.2020.6.3

\begin{abstract}
Objectives: To explore the privileges of pharmacists through the clinical and administrative activities in Saudi Arabia. Methods: This is a 4-month cross-sectional survey regarding clinical and administrative privileges of pharmacists in Saudi Arabia. The study consisted of two parts: the first part collected demographic information and the second part comprised a questionnaire with 28 questions divided into 4 domains. The questions were derived from previous literature and from the regulatory standards of the American Society of Health-System Pharmacists (ASHP). The four domains were as follows: privilege management and resources, pharmacist prescribing and therapeutic interchange, clinical and administration privilege and drug monitoring and healthcare education. The responses were obtained using a 5-point Likert response scale system with close- and open-ended questions. The survey questionnaire was distributed in an electronic format to the director of pharmacy of each hospital in Saudi Arabia. In this study, we analyzed pharmacist's privilege in Saudi Arabia with regard to the clinical and administrative activities. All data were obtained through the Survey Monkey system. Results: The survey was distributed to 36 hospitals. The average score of pharmacist privilege in the hospital pharmacy practice program was $3.16(63.13 \%)$. Most of the pharmacy practice programs having pharmacist privilege were nonformulary requests $(3.69(73.8 \%))$, patient counseling $(3.60(72 \%))$ and medication errors preventing and monitoring $(3.58(71.6 \%))$. The average score of clinical privilege for a pharmacist was $2.95(58.97 \%)$. The maximum score of clinical privileges for a pharmacist were to answer questions from all healthcare professionals $(3.83(76.6 \%))$, to decrease drug dosing $(3.47(69.4 \%))$ and to change drug strength (3.4 (68\%)). The average score of pharmacist administration privilege was $3.14(62.75 \%)$. The administration privileges for pharmacists were to conduct educational courses $(3.81(76.2 \%))$ followed by to setup vision and mission $(3.71(74.20 \%))$ and to conduct training programs $(3.64(72.80 \%))$. Conclusion: The clinical and administrative privileges of a pharmacist is not well established in the Kingdom of Saudi Arabia. Most of the clinical and administrative privileges were regular and primary duties. Therefore, it is important to update the policies and procedures of clinical and administrative privileges given to a pharmacist with more engagement in the pharmacy practice. These practices are highly recommended in order to improve pharmaceutical care implementation at hospitals in the Kingdom of Saudi Arabia.

Key words: Privileges, Pharmacist, Clinical, Administrative, Activities, Saudi Arabia.
\end{abstract}

\section{INTRODUCTION}

The healthcare system is changing rapidly with an increase in complexity. The healthcare organizations need to authorize privileges to certain professionals in order to validate their capabilities and competencies with a focus on patient's medical needs and health outcomes. ${ }^{1}$ The benefits of a pharmacist privilege program are extensive, especially for providing services, care and also treatment to the patients. The pharmacists should be committed to continuous and extensive professional development in order to meet the annual validation requirements with rigorous standards. Therefore, the pharmacists must ensure that they are actively performing each privilege and remain current on changes related to operational and clinical practice where the primary goal is to translate the privileging process into an up-to-date confident pharmacist who is efficient and aware. This might lead to improved safety and patient care outcomes. Organizations may require specific credentials such as the board of pharmacy specialty certifications to demonstrate their capabilities and competencies of a pharmacist. ${ }^{1}$ In addition, pharmacists at their institutions will need to gain a thorough understanding of the privileging and credentialing processes. However, institutions may differ from each other; therefore, there are standard methods of managing and implementing the privileging and credentialing processes. ${ }^{2}$ The clinical pharmacy activities might be divided into central clinical pharmacy activities, patient-focused clinical pharmacy activities and administration clinical pharmacy activities. ${ }^{3-7}$ Multiple clinical pharmacists provide central clinical pharmacy activities, drug information, drug utilization evaluation and pharmacy education and training services. Many clinical pharmacists have the traditional roles of rounding with the healthcare team; others are also part of pharmacist-run clinics. Available pharmacist-run clinics include solid organ transplant, cardiology, anticoagulation, ambulatory care, pain and oncology through patient-focused clinical pharmacy activities. Other clinical pharmacists spend their time with administrative activities, clinical pharmacy activities through pharmacy and therapeutic committee, setup therapeutic protocol and guidelines, 
administration-related issues in the pharmacy practice..$^{3-5}$ All types of clinical pharmacy activities have established the privilege of pharmacists through collaborative practice agreements with physicians; such agreements give the pharmacists for instant prescriptive authority. ${ }^{8}$ According to the terms of the agreement, the pharmacists can order medications and laboratory tests independently or countersign by the physician. For pressing issues that need to be addressed, many hospitals have 24-hr clinical coverage through an on-call clinical pharmacist to cover some clinical activities that need more pharmacist's privileges. Many clinical pharmacists serve as preceptors for residents and students and can teach at affiliated universities in addition to delivering their clinical duties. Moreover, some institutions highly encourage clinical pharmacists to take the field of research and publishing with full documented privilege. ${ }^{9}$ Some hospitals specify some key performance indicators to measure the clinical pharmacist's contribution to patient care and evaluate some of the impacts of clinical pharmacists. ${ }^{10,11}$ As a result, majority of the studies have discussed the clinical pharmacist activities or performances or workload; however, to the best of our knowledge there are no studies related to the privilege of the clinical and administrative activities in Saudi Arabia, Middle Eastern countries, or in rest of the world. ${ }^{6,7}$ Therefore, in this study, we aimed to declare the privilege of clinical and administrative activities in the KSA.

\section{METHODS}

This is a 4-month cross-sectional survey regarding privileges of pharmacists in Saudi Arabia. The study consisted of two parts: the first part collects demographic information and the second part comprises a questionnaire with 28 questions divided into 4 domains. These domains are derived from previous literature and from the guidelines and regulations stated by the ASHP.,12-15 The four sections are as follows: privilege management and resources, pharmacist prescribing and therapeutic interchange, clinical and administration privilege and drug monitoring and healthcare education. The responses were obtained via a 5-point Likert response scale system with close and open-ended questions. The survey was distributed in an electronic format and was distributed to the director of pharmacy, deputy director, pharmacy quality management, clinical pharmacy coordinators, or to any pharmacist assigned on behalf of director of pharmacy. The follow-up was done via email and telephone after every 1-2 weeks. All primary healthcare centers and regional pharmacy administration at MOHs were excluded from the study. In this study, we analyzed clinical and administrative privileges of pharmacists in Saudi Arabia. All data were obtained through the Survey Monkey system and analyzed using Statistical Package of Social Sciences (SPSS) version 20 . The data were validated via three different methods: three authors reviewed the survey independently and a pilot study was conducted. Then, the survey was updated accordingly and the Cronbach's alpha value for internal validity was calculated. The survey was exempted from the international guidelines of institutional review boards (IRB). ${ }^{16}$

\section{RESULTS}

The survey was distributed to 36 hospitals. Of them, $19.44 \%$ of the hospitals had 100-199 beds and less than 50 beds, while 13.89\% had 50-99 beds, 300-399 and more than 600 beds) hospitals. Of the total 36 hospitals, 18 (50.00\%) hospitals were accredited by the CBAHI, 17 (47.22\%) were accredited by the Saudi Commission of Health Specialties and 13 (36.11\%) were accredited by the Joint Commission, whereas 5 (13.89\%) hospitals had no accreditation from any of the organization and 13 (36.11\%) hospitals were covered by $50-74 \%$ of the patient medical cost by health insurance. Majority of the responders were in the age group of 41-65 years $(17(47.22 \%))$. Majority of the responders were Saudi nationals (32 (88.89\%)); 4 (11.11\%) among responders were non-Saudi nationals. Most of the responders had Diploma in Pharmacy degree (14 (38.89\%)) and Bachelor of Science in Pharmacy degree (12 (33.33\%)). Most of the responders had $<1$ year experience in pharmacy $(46.67 \%)$, whereas $30.77 \%$ of the responders had $4-6$ years of experience in clinical pharmacy and $43.75 \%$ had $>6$ years of experience in pharmacy administration (Tables 1 and 2). The average score of pharmacist privilege in the hospital pharmacy practice program was 3.16 (63.13\%). Most of the pharmacy practice programs having pharmacist privilege was nonformulary request $(3.69(73.8 \%))$ followed by patient counseling $(3.60$ $(72 \%))$ and medications errors preventing and monitoring $(3.58(71.6 \%))$ (Table 3). The average score of clinical privilege for a pharmacist was $2.95(58.97 \%)$. Most of the clinical privileges for a pharmacist was for answer questions from all healthcare professionals $(3.83(76.6 \%))$ followed by decrease drug dosing (3.47 (69.4\%)) and change drug strength $(3.4(86 \%))$ (Table 4$)$. The average score of administrative privilege for a pharmacist was 3.14 (62.75\%). Most of the administrative privilege for a pharmacist was for conduct educational courses $(3.81(76.2 \%))$ followed by setup vision and mission $(3.71(74.20 \%))$ and conduct training programs $(3.64(72.80 \%))$ (Table 5). The Cronbach's alpha value was 0.983 .

\section{DISCUSSION}

In $\mathrm{MOH}$ hospitals of Riyadh city, where the clinical pharmacy services were begun in the mid-1980s and progressed in the mid-1990s and late 2000s, these services were positively accepted by the medical and surgical departments and drug information services. After that, the services were expanded to cover pharmacy research and clinical trials. The clinical pharmacist began drug utilization evaluation program and also started to prepare TPN. Their roles were expanded to full-time with different specialty clinical pharmacy staff organized at oncology services, anticoagulation services, surgical orthopedic services, pain management services and poisoning services. ${ }^{17}$ The pharmacy administration at $\mathrm{MOH}$ began with more than 30 consistent clinical pharmacy programs at 20 regions in the KSA. Each program had the central committee with expert representatives from different areas. The council had a strategic plan for each application with specialized training and education facilities. Each clinical pharmacy program began with a little number of hospitals; then, they expanded thoroughly including The job description with three levels of clinical pharmacists career. ${ }^{18}$ In daily practice, the pharmacist performs several activities, for example, clinical or central activities, patientrelated activities and administration activities. ${ }^{19}$ However, the privileges of each activity were not involved elements among the pharmacy law of the Kingdom of Saudi Arabia (KSA). This study revealed three types of privileges in practice. In this study, we aimed to measure pharmacist privilege in clinical and administrative activities of pharmacy practice in Saudi Arabia. Our results showed that the pharmacist privilege founded among two-thirds of the pharmacy practice program, which represents daily activities that includes requesting nonformulary medications, patient counseling, drug-related problems of medication errors and adverse drug reactions. ${ }^{20}$ While half of the programs had the privilege of the pharmacist, for instance, nutrition support and perform research and publications and providing pharmacokinetic services at home.

Our results were found to be better than what has been reported by Alomi et al. in terms of patient counseling and reporting of adverse drug reactions, whereas our results were not better than Alomi et al. in terms of medication errors preventing and monitoring, but the highest average score was recorded for nonformulary request program. ${ }^{20}$ This is predictable because the first clinical pharmacy program was started at hospitals in Saudi Arabia after implementation of the updated pharmacy strategic planning. $\mathrm{MOH}$ administration focused more on medication errors, whereas the Saudi Food and Drug Authority focused more on adverse drug reactions. ${ }^{21-23}$ However, the other clinical pharmacy services still need more development. Half of the activities had clinical privilege, 


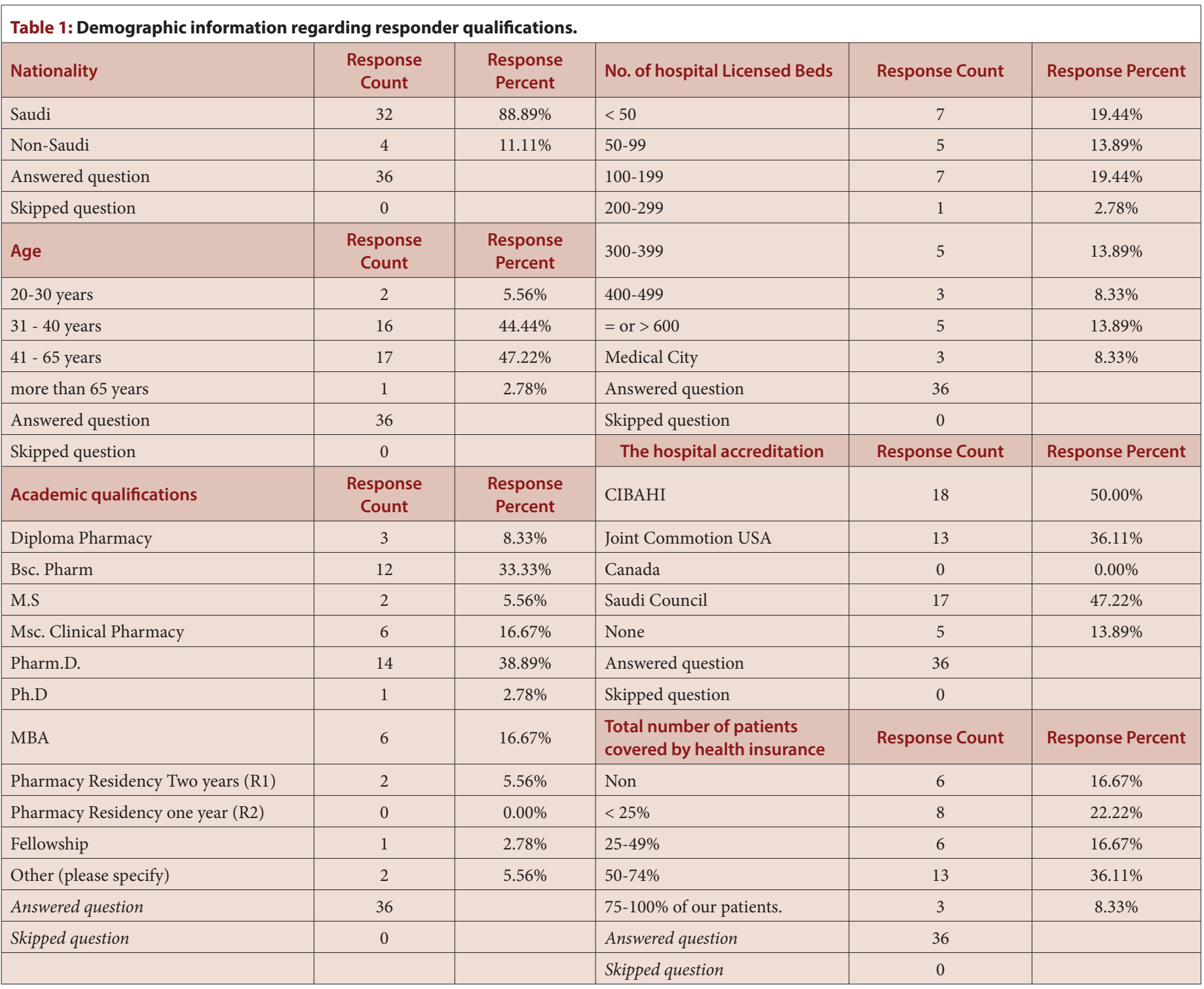

\begin{tabular}{|c|c|c|c|c|c|c|c|}
\hline Years of experience & Pharmacy Practice & Percent & $\begin{array}{c}\text { Clinical } \\
\text { Pharmacy }\end{array}$ & Percent & $\begin{array}{c}\text { Pharmacy } \\
\text { Administration }\end{array}$ & Percent & Response Count \\
\hline 0 & 4 & $30.77 \%$ & 4 & $30.77 \%$ & 5 & $38.46 \%$ & 13 \\
\hline$<1$ year & 7 & $46.67 \%$ & 4 & $26.67 \%$ & 4 & $26.67 \%$ & 15 \\
\hline $1-3$ & 9 & $39.13 \%$ & 6 & $26.09 \%$ & 8 & $34.78 \%$ & 23 \\
\hline $4-6$ & 7 & $26.92 \%$ & 8 & $30.77 \%$ & 11 & $42.31 \%$ & 26 \\
\hline$>6$ years & 14 & $43.75 \%$ & 4 & $12.50 \%$ & 14 & $43.75 \%$ & 32 \\
\hline Answered question & & & & & & & 36 \\
\hline Skipped question & & & & & & & 0 \\
\hline
\end{tabular}

whereas the majority of the clinical activities among pharmacist clinical privilege were answering drug information inquiries or dosing reductions and change of drug strength. Requesting discounted laboratory test, administered medications, or requesting medications devices were the activities having lowest clinical privilege for pharmacist because they might be taken care by the administration of the hospital though they were not included in pharmacist job. The pharmacist may need to follow medications and need to request some laboratory tests to ensure the efficacy and safety of the medications. The pharmacist did an excellent role with administration vaccines during immunization programs elsewhere. ${ }^{24,25}$ According to our results, administrative privilege was higher than a clinical privilege. Providing training and education or setting up vision and mission were the most implemented administrative privilege because they considered these as daily activities and were part of the pharmacist job. While the lowest administrative privilege was for performing research or participate in the clinical trial or publications of 


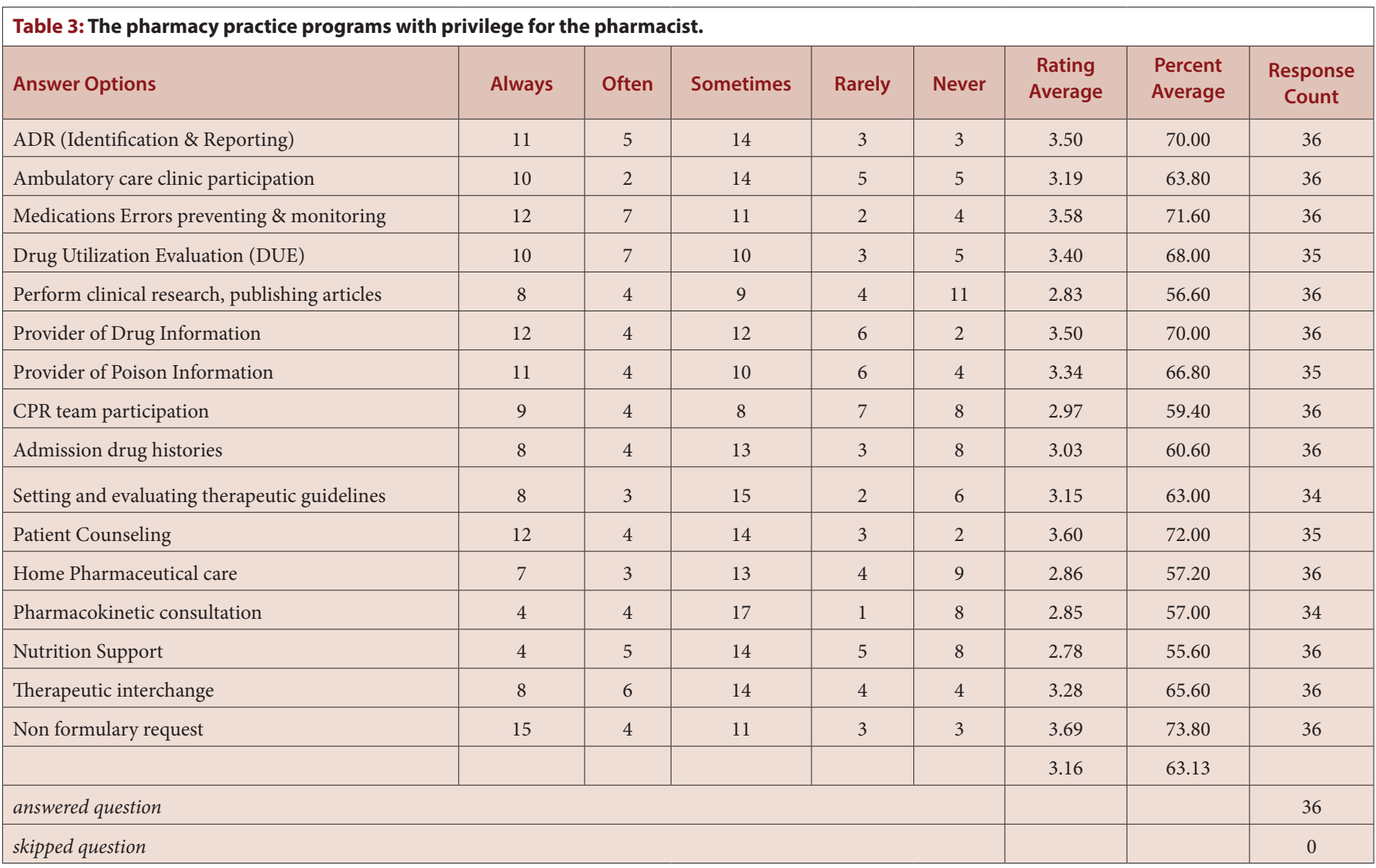

\begin{tabular}{|c|c|c|c|c|c|c|c|c|}
\hline Answer Options & Always & Often & Sometimes & Rarely & Never & $\begin{array}{l}\text { Rating } \\
\text { Average }\end{array}$ & $\begin{array}{l}\text { Percent } \\
\text { Average }\end{array}$ & $\begin{array}{c}\text { Response } \\
\text { Count }\end{array}$ \\
\hline Prescribe new medication & 6 & 8 & 12 & 4 & 6 & 3.11 & 62.20 & 36 \\
\hline Reorder medications & 10 & 4 & 12 & 3 & 7 & 3.19 & 63.80 & 36 \\
\hline Hold the medications & 8 & 6 & 15 & 3 & 3 & 3.37 & 67.40 & 35 \\
\hline Discontinue the medication & 6 & 4 & 16 & 4 & 4 & 3.12 & 62.40 & 34 \\
\hline Increase drug dosing & 8 & 4 & 16 & 2 & 5 & 3.23 & 64.60 & 35 \\
\hline Decrease drug dosing & 8 & 9 & 11 & 3 & 3 & 3.47 & 69.40 & 34 \\
\hline Change the dosage form & 8 & 5 & 16 & 1 & 5 & 3.29 & 65.80 & 35 \\
\hline Change drug strength & 9 & 6 & 14 & 2 & 4 & 3.40 & 68.00 & 35 \\
\hline Request lab test & 6 & 4 & 13 & 5 & 7 & 2.91 & 58.20 & 35 \\
\hline Discontinue lab test & 8 & 3 & 12 & 3 & 9 & 2.94 & 58.80 & 35 \\
\hline Request radiology test & 3 & 1 & 9 & 6 & 15 & 2.15 & 43.00 & 34 \\
\hline Request minor surgical procedure & 4 & 1 & 11 & 4 & 15 & 2.29 & 45.80 & 35 \\
\hline Request major surgical procedure & 4 & 0 & 11 & 5 & 16 & 2.19 & 43.80 & 36 \\
\hline Administer the medications & 7 & 3 & 9 & 6 & 9 & 2.79 & 55.80 & 34 \\
\hline Request medication administration devices & 7 & 1 & 16 & 5 & 7 & 2.89 & 57.80 & 36 \\
\hline Answer questions from all healthcare professionals & 15 & 4 & 13 & 1 & 2 & 3.83 & 76.60 & 35 \\
\hline Average & & & & & & 2.95 & 58.97 & \\
\hline \multicolumn{6}{|l|}{ answered question } & & & 36 \\
\hline \multicolumn{6}{|l|}{ skipped question } & & & 0 \\
\hline
\end{tabular}




\begin{tabular}{|c|c|c|c|c|c|c|c|c|}
\hline Answer Options & Always & Often & Sometimes & Rarely & Never & $\begin{array}{l}\text { Rating } \\
\text { Average }\end{array}$ & $\begin{array}{l}\text { Percent } \\
\text { Average }\end{array}$ & $\begin{array}{l}\text { Response } \\
\text { Count }\end{array}$ \\
\hline Setup up strategic plan & 8 & 7 & 11 & 6 & 3 & 3.31 & 66.20 & 35 \\
\hline Setup vision and mission & 16 & 2 & 11 & 3 & 3 & 3.71 & 74.20 & 35 \\
\hline Setup goals and values & 14 & 4 & 12 & 2 & 4 & 3.61 & 72.20 & 36 \\
\hline Setup policy and procedures & 11 & 9 & 10 & 2 & 3 & 3.66 & 73.20 & 35 \\
\hline Request number of staff workforce & 10 & 9 & 12 & 1 & 4 & 3.56 & 71.20 & 36 \\
\hline Request type of staff workforce & 11 & 8 & 12 & 2 & 3 & 3.61 & 72.20 & 36 \\
\hline $\begin{array}{l}\text { New pharmacy staff interview and agreement of } \\
\text { final contract }\end{array}$ & 10 & 5 & 13 & 4 & 4 & 3.36 & 67.20 & 36 \\
\hline Setup the pharmacy financial budget & 5 & 4 & 13 & 7 & 7 & 2.81 & 56.20 & 36 \\
\hline Setup key performance indicators & 11 & 6 & 12 & 2 & 5 & 3.44 & 68.80 & 36 \\
\hline Setup the cost of services & 6 & 2 & 12 & 8 & 8 & 2.72 & 54.40 & 36 \\
\hline Setup the prices of medications & 6 & 4 & 11 & 5 & 9 & 2.80 & 56.00 & 35 \\
\hline Exchange medications with governmental hospitals & 9 & 5 & 12 & 4 & 5 & 3.26 & 65.20 & 35 \\
\hline Exchange medications with private hospitals & 9 & 1 & 11 & 8 & 5 & 3.03 & 60.60 & 34 \\
\hline Perform pharmacy research & 7 & 3 & 12 & 6 & 8 & 2.86 & 57.20 & 36 \\
\hline Perform drug clinical trails & 7 & 2 & 14 & 4 & 9 & 2.83 & 56.60 & 36 \\
\hline Purplish research in the biomedical journals & 7 & 1 & 10 & 8 & 10 & 2.64 & 52.80 & 36 \\
\hline Setup pharmacy committees & 11 & 7 & 13 & 1 & 3 & 3.63 & 72.60 & 35 \\
\hline Sign low come pharmacy staff & 6 & 2 & 16 & 5 & 7 & 2.86 & 57.20 & 36 \\
\hline $\begin{array}{l}\text { Prepare the pharmacy for national and international } \\
\text { accreditation }\end{array}$ & 9 & 9 & 13 & 1 & 3 & 3.57 & 71.40 & 35 \\
\hline Conduct education courses & 13 & 7 & 14 & 0 & 2 & 3.81 & 76.20 & 36 \\
\hline Conduct training programs & 12 & 7 & 13 & 0 & 4 & 3.64 & 72.80 & 36 \\
\hline Average & & & & & & 3.14 & 62.75 & \\
\hline \multicolumn{6}{|l|}{ answered question } & & & 36 \\
\hline \multicolumn{6}{|l|}{ skipped question } & & & 0 \\
\hline
\end{tabular}

biomedical journals that's related to the healthcare administration might gave the responsibilities to other healthcare providers. Therefore, we recommend that the clinical and administrative privilege for pharmacists should be revised that are related to the changing roles of a pharmacy job from being product-centered to being patient-centered, which requires authorization of various clinical and administrative privileges to a pharmacist. Further studies should be conducted periodically to measure the implementation of clinical and administrative privileges for pharmacists in the KSA.

\section{CONCLUSION}

The clinical and administrative privilege of a pharmacist in Saudi Arabia was not optimum in practice. Majority of the clinical and administrative privileges of a pharmacist were found to be basic and common practice duties. Therefore, it is highly recommended to establish clinical and administrative privileges for pharmacists in order to improve patient care and implement the quality management standers as part of the accreditation process of healthcare organizations. The implementation of pharmacist privilege of clinical and administrative pharmacy is highly required in the KSA.

\section{ACKNOWLEDGEMENT}

None.

\section{CONFLICT OF INTEREST}

The authors declare no conflicts of interest.

\section{ABBREVIATIONS}

MOH: Ministry of Health; KSA: Kingdom of Saudi Arabia; CBAHI: Saudi Central Board for Healthcare Accreditation; ASHP: American Society of Health-System Pharmacists; SPSS: Statistical Package of Social Sciences; TPN: Total parenteral nutrition.

\section{REFERENCES}

1. Jordan TA, Hennenfent JA, Lewin JJ, Nesbit TW, Weber R. Elevating pharmacists' scope of practice through a health-system clinical privileging process. Am J Heal Pharm. 2016;73(18):1395-405.

2. The Joint Commision Accreditation Ambulatory care. Ambulatory Care Program: The Who, What, When, and Where's of Credentialing and Privileging. The Joint Commision Accreditation Ambulatory care. [Internet]. [cited 2020 Feb 19]. Available from: https://www.jointcommission.org/assets/1/6/AHC_who_what_ when_and_where_credentialing_booklet.pdf

3. Bond CA, Raehl CL. Clinical pharmacy services, pharmacy staffing and hospital mortality rates. Pharmacotherapy. 2007;27(4):481-93.

4. Bond CA, Raehl CL, Franke T. Clinical Pharmacy Services, Pharmacist Staffing and Drug Costs in United States Hospitals. Pharmacotherapy. 1999;19(12):135462.

5. Bond CA, Raehl CL. Clinical pharmacy services, pharmacy staffing and adverse drug reactions in United States hospitals. Pharmacotherapy. 2006;26(6):735-47.

6. Alomi YA, Aldosary BA. Cost Analysis of Activities for Network Drug Information 
Centers at the Ministry of Health Hospitals in Saudi Arabia. Int J Pharm Heal Sci. 2019;2(1):45-51.

7. Alomi YA, Alghamdi SJ, Alattyh RA. National Workload Analysis of Network of Drug Information Centers at Ministry of Health Hospitals in Saudi Arabia. Int $J$ Pharmacol Clin Sci. 2018;7(4):17-25.

8. Alomi YA, Alghamdi SJ, Alattyh RA, Shorog E, Alshahran A, Alasmary S, et al. National Survey of Pharmacy Practice at Ministry of Health Hospitals in Saud Arabia 2016-2017: Prescribing and Medication Management. J Pharm Pr Community Med. 2018;4(1S):S54-9.

9. Alomi YA, Aldosori N, Alhadab M, Alotaibi NR, Al-Shubbar N, Al-Enazi ADM, et al. The Outcomes of Clinical Pharmacist Consultation Visits at Ministry of Health Hospitals in Saudi Arabia: Medication Safety and Pharmacy Research. J Pharm Pract Community Med. 2017;3(3):168-75

10. Alomi YA. National Pharmacy Pain Management Program at Ministry of Health in Saudi Arabia. J Pharmacol Clin Res. 2017;3(2):1-7.

11. Alomi YA. National Antimicrobial Stewardship Program in Saudi Arabia: Initiative and the Future. Open Access J Surg. 2017;4(5):1-7.

12. Burns AL. Credentialing and Privileging of Pharmacists: A Resource Paper from the Council on Credentialing in Pharmacy Council. Consult Pharm. 2015;29(11):757-70.

13. Guirguis LM, Hughes CA, Makowsky MJ, Sadowski CA, Schindel TJ, Yuksel $\mathrm{N}$. Survey of pharmacist prescribing practices in Alberta. Am J Heal Pharm. 2017;74(2):62-9.

14. Blair MM, Carmichael J, Young E, Thrasher K. Pharmacist privileging in a health system: Report of the Qualified Provider Model Ad Hoc Committee. Am J Heal Pharm. 2007;64(22):2373-81.
15. Christel GS. Clinical Pharmacist Credentialing and Privileging: A Process for Ensuring High-Quality Patient Care. Parctioner Forum. 2019;36(4):155-7.

16. The Office for Human Research Protections. Human Subject Regulations Decision Charts. Chart. 2016. [cited 2019 Nov 4]. Available from: https://www.hhs. gov/ohrp/regulations-and-policy/decision-charts/index.html

17. Alomi YA. National Pharmacy Practice Programs at Ministry of Health in Saudi Arabia. J Pharm Pharm Scien. 2015;1(2):17-8.

18. Alomi Y. National Pharmacy Administration Programs. BAOJ Pharm Sci. 2015;1(2):1-2

19. Bond CA, Raehl CL. Clinical pharmacy services, pharmacy staffing and hospital mortality rates. Pharmacotherapy. 2007;27(4):481-93.

20. Alomi YA, Alghamdi SJ, Alattyh RA. National Survey of Pharmacy Practice at MOH Hospitals in Saudi Arabia 2016-2017: Clinical Pharmacy Services. J Pharm Pr Community Med. 2018;4(1):1S-8S.

21. YA A. National Drug Information Center Program at Ministry of Health in Saud Arabia. Adv Pharmacoepidemiol Drug Saf. 2016;5(1):1-2.

22. Alomi YA. National Medication Safety Program at Ministry of Health in Saudi Arabia. J Pharmacovigil. 2015;3(5):e145

23. Saudi Food and Drug Authority. List of human medicine and herbal health. Herbal and Health Drugs. 2019. [Cited 2019 Jun 17]. Available from: https://www. sfda.gov.sa/en/drug/resources/Pages/DrugsUnderRegistrations.aspx

24. American Society of Health-System Pharmacists. ASHP guidelines on the pharmacist's role in immunization. Am J Heal Pharm. 2003;60(13):1371-7.

25. Higginbotham S, Stewart A, Pfalzgraf A. Impact of a pharmacist immunizer on adult immunization rates. J Am Pharm Assoc. 2012;52(3):367-71. 